\title{
Prevalence of gastrointestinal parasites in communal goats from different agro-ecological zones of South Africa
}

\author{
Takalani J. Mpofu, Khathutshelo A. Nephawe and Bohani Mtileni
}

Department of Animal Sciences, Tshwane University of Technology, Private Bag X680, Pretoria 0001, South Africa.

Corresponding author: Takalani J. Mpofu, e-mail: mpofutj@tut.ac.za

Co-authors: KAN: nephaweka@tut.ac.za, BM: mtilenib@tut.ac.za

Received: 10-04-2019, Accepted: 02-12-2019, Published online: 04-01-2020

doi: www.doi.org/10.14202/vetworld.2020.26-32 How to cite this article: Mpofu TJ, Nephawe KA, Mtileni B (2020) Prevalence of gastrointestinal parasites in communal goats from different agro-ecological zones of South Africa, Veterinary World, 13(1): 26-32.

\begin{abstract}
Aim: A longitudinal study was conducted to assess the epidemiology of common gastrointestinal parasite (GIP) infections affecting goats in South Africa as influenced by agro-ecological zone (AEZ), sampling season, and the age and sex of animals.

Materials and Methods: A total of 288 goats (101 male and 187 female) were randomly sampled during winter and summer in areas representing four AEZs (arid: 80; semi-arid: 76; humid: 62; and dry sub-humid: 70) of South Africa. Fecal samples from each animal were collected from the rectum, and the presence of GIP eggs was determined using a modified McMaster technique. A sample was considered positive when a minimum of one GIP egg was detected under the microscope. Fecal cultures were prepared, and infective larvae were collected and identified. The data were analyzed by MiniTab17 (2017) using the FREQ procedure, and the association between the independent factors and the prevalence of various GIPs were evaluated using the Pearson Chi-square test $(\mathrm{p}<0.05)$.
\end{abstract}

Results: The overall prevalence of GIP in the present study was 37.1\%, with a mean prevalence of 30.0, 26.4, 31.1, 36.6, and 59.6\% for Eimeria spp., Trichuris, Strongyloides papillosus, Moniezia spp., and strongyles, respectively. There was a significant $(\mathrm{p}<0.05)$ association between the prevalence of strongyles, Trichuris, Moniezia spp., and AEZs, whereas an insignificant ( $>0.05)$ association was observed for the prevalence of Eimeria spp. and S. papillosus. A significant ( $<00.05)$ association between goat age and prevalence of all GIPs was observed, where the prevalence was higher in young goats, followed by adults, and then by suckling goats. The prevalence of various GIPs was similar between male and female goats. The percentage of infection with Eimeria spp., Trichuris, S. papillosus, and strongyle parasitic infections was marginally higher in males than in females, whereas that of the Moniezia spp. was higher in females. A significant $(\mathrm{p}<0.05)$ association between the prevalence of Eimeria spp. and sampling season was observed, and there was an insignificant ( $\mathrm{p}>0.05$ ) association between the other GIPs and sampling season. The prevalence of Eimeria spp. infection was higher in winter $(34.0 \%)$ than in summer $(26.0 \%)$.

Conclusion: AEZs and goat age are the most important risk factors influencing GIP infections in South African communal goats. These epidemiological parameters are important for outlining effective parasite control management systems against these GIPs in goats.

Keywords: Eimeria, Moniezia, strongyle, Strongyloides papillosus, Trichuris spp.

\section{Introduction}

In the various agro-ecological zones (AEZs) of South Africa, goats are reared to fulfill multiple purposes and to meet nutritional, economic, and socio-cultural needs [1-3]. Their existence in rural households serves as a cushion in the event of crop failures due to various reasons, including climatic vagaries, especially in arid and semi-arid environments. The rich potential of the small ruminant sector, which includes goats, is not efficiently exploited due to several constraints including malnutrition, inefficient management, and diseases [4].

Copyright: Mpofu, et al. Open Access. This article is distributed under the terms of the Creative Commons Attribution 4.0 International License (http://creativecommons.org/licenses/by/4.0/), which permits unrestricted use, distribution, and reproduction in any medium, provided you give appropriate credit to the original author(s) and the source, provide a link to the Creative Commons license, and indicate if changes were made. The Creative Commons Public Domain Dedication waiver (http://creativecommons.org/ publicdomain/zero/1.0/) applies to the data made available in this article, unless otherwise stated.
Goats are highly susceptible to gastrointestinal parasites (GIPs) [5,6] due to their lower innate immune response against specific helminths as a result of their evolution [7-9] and the nomadic nature of goat husbandry. In this regard, among the production constraints of goats that contribute to production losses in rural communities, GIPs constitute a major share $[10,11]$. The challenge is, however, much more severe in tropical countries due to favorable environmental conditions for GIP transmission [12,13], poor nutrition of the host animals [14], and poor sanitation in rural areas [15]. This makes controlling GIPs the most important health issue in goats of all ages [16-18]. The prevalence of GIP infection in livestock varies according to their existing managemental practices $[19,20]$, season of the year $[21,22]$, and animal age [23-25] and sex [26-28]. Several epidemiological studies have been carried out on GIPs in goat communities in South Africa [29-31], but these studies were limited in scope and coverage, sample 
size, and risk factors considered. Sound GIP control strategies have not yet been established with respect to the AEZs of South Africa. Therefore, it is essential to estimate the possible variation in parasitic infection in goats in different geographical regions, which could aid in designing effective control measures against parasitic diseases.

Hence, to reduce the gap in knowledge of the epidemiology of GIP infections in communal goats in different AEZs in South Africa, this study was conducted to assess the epidemiology of common gastr intestinal parasitic infections affecting goats as influenced by AEZ, sampling season, and animals' age and sex.

\section{Materials and Methods}

\section{Ethical approval}

The study was approved by the Animal Research Ethics Committee of the Faculty of Science, Tshwane University of Technology [FCRE 2017/10/01 (02) (SCI)]. Ethical concerns were taken into account by adhering to the local animal welfare regulations and practices, and experiments conformed to the ethical guidelines for animal usage in the research of Tshwane University of Technology, South Africa.

\section{Study site and animal management}

This longitudinal study was conducted in different AEZs: Arid, semi-arid, humid, and dry sub-humid zones, of KwaZulu-Natal, Limpopo, and Mpumalanga Provinces of South Africa. Goats sampled were owned by smallholder farmers who had small flock sizes ranging from one to ten animals. The selected AEZs varied in percentage of land surface, rainfall distribution, and length of the growing period. Animals were kept under extensive grazing systems where during the day they were released to graze on communal lands and corralled at night. In these areas, veterinary care was low to non-existent, and goats were not treated or dewormed. A total of 288 goats $(101$ male and 187 female) were randomly sampled during winter (June-July) and summer (November-December) in areas representing four AEZs (arid: 80, semi-arid: 76, humid: 62 , and dry sub-humid: 70). Goats were classified by age (suckling: < 1 year, young: 1-3 years, and adult: $>3$ years) as described by Kheirandish et al. [32]. Plastic ear tags $\left(\mathrm{Allflex}^{\circledR}\right)$ bearing individual identification numbers were placed on the right ear of each animal sampled to allow for repeated use of the same animals over the study period.

The sample size was determined using the following equation:

$$
\text { Sample size }=\frac{1.96^{2} \mathrm{pq}}{L^{2}}
$$

Where, $\mathrm{n}=$ sample size, $\mathrm{p}=$ expected prevalence, $\mathrm{q}=1-\mathrm{p}$, and $\mathrm{L}=$ limits of error on the prevalence. Because the prevalence in the local goat population was unknown, the hypothesized prevalence of $75 \%$ was used with a $5 \%$ limit of error of the prevalence.
The required sample size was calculated to be 288 goats [33].

\section{Fecal collection and coprology}

About 10-g fecal samples from each animal were collected twice in each season directly from the rectum into airtight containers. Samples were maintained at $2-4^{\circ} \mathrm{C}$ in cooler boxes and were transported to the laboratory within $24 \mathrm{~h}$ for further coprological examination. The fecal samples were examined for the presence of GIP eggs. The fecal eggs per gram counts were determined by a modified McMaster technique, as described by Hansen and Perry [34]. The floatation fluid used was sodium chloride ( $\mathrm{NaCl}: 500 \mathrm{~g}$, Water: $1000 \mathrm{~mL}$ ). The fecal samples were ground into five drops of bloat guard to prevent bubbles when counting the eggs. The GIPs were identified under a compound microscope $(10 \times)$ based on the morphological appearance and size of helminth eggs, protozoa cysts, and trophozoites [35,36]. Distinguishable nematode (Trichuris), trematode, and cestode eggs were identified directly. A sample was considered positive when a minimum of one GIP egg was detected under the microscope. Fecal cultures were prepared by incubating 2-3 g of feces between $26^{\circ} \mathrm{C}$ and $28^{\circ} \mathrm{C}$ for 7 days at $80 \%$ humidity after which infective larvae were collected using a modified Baermann technique. $\mathrm{L}_{3}$-stage nematodes were identified according to the protocol proposed by Van Wyk et al. [37]. Eimeria species were identified following the sporulation of oocysts within the feces in a thin layer of $2.5 \%$ potassium dichromate for 1 week between $26^{\circ} \mathrm{C}$ and $28^{\circ} \mathrm{C}$. The identification of Eimeria species was based on morphological characteristics of oocysts (size, shape, color, and presence or absence of a micropyle and its cap). The prevalence was determined using the following equation:

$$
\text { Prevalence }(\%)=\frac{\mathrm{a}}{\mathrm{b}} \times 100
$$

Where, "a" = Number of individuals having a disease at a particular time; "b" = Number of individuals in the population at risk at that point in time [38].

\section{Statistical analysis}

The data were analyzed by a MiniTab17 [39] using the FREQ procedure and the association between the independent factors (AEZ, goat age and sex, and sampling season) and the prevalence of various GIP were evaluated using the Pearson Chi-square test at a significance threshold at $\mathrm{p}<0.05$.

\section{Results}

The $\mathrm{L}_{3}$ nematodes identified from the fecal cultures of all animals were Haemonchus spp., Strongyloides papillosus, and Oesophagostomum spp. in arid, semiarid, and humid zones. Haemonchus and S. papillosus were identified in the dry sub-humid zone. Regarding Eimeria spp., Eimeria arloingi, Eimeria christenseni, Eimeria alijevi, Eimeria jolchijevi, Eimeria caprina, Eimeria caprovina, and Eimeria hirci were identified in fecal cultures from all AEZs. The prevalence 
of various GIPs in different AEZs of South Africa is presented in Table-1. Five types of GIP eggs observed were Eimeria spp., Trichuris, S. papillosus, Moniezia spp., and strongyle eggs, with an overall prevalence of $30.0,26.4,31.1,36.6$, and $59.6 \%$, respectively. There was a significant $(\mathrm{p}<0.05)$ association between the prevalence of strongyles, Trichuris, and Moniezia spp. The AEZ with the highest GIP prevalence was the humid zone. There was an insignificant $(\mathrm{p}>0.05)$ association between the prevalence of Eimeria spp., $S$. papillosus, and AEZ. The nematode infections showed a preponderance of strongyle eggs, while S. papillosus, Trichuris, and Moniezia spp. infections were sporadic in different AEZs.

Pearson Chi-square analysis showed a significant $(p<0.05)$ association between the prevalence of all GIPs and goat age (Table-2). A higher prevalence of all GIPs was observed in young goats $(53.8 \%)$, followed by adult goats $(35.7 \%)$ and finally in suckling goats $(20.0 \%)$. Strongyle infections showed a prevalence of $76.4,61.1$, and $31.8 \%$ in young, adult, and suckling goats, respectively. Sporadic infection by all GIPs was observed in goats of different ages.
There was an insignificant $(\mathrm{p}>0.05)$ association between the prevalence of all GIPs and the goats' sex (Table-3). The prevalence of Eimeria spp., Trichuris, S. papillosus, Moniezia spp., and strongyle eggs in male goats was $31.7,28.7,34.7,34.2$, and $62.4 \%$, respectively, while the corresponding values in females were 29.1, 25.1, 29.1, 38.0, and 58.0\%, respectively.

There was a significant $(\mathrm{p}<0.05)$ association between the prevalence of Eimeria spp. and sampling season, while there was an insignificant $(\mathrm{p}>0.05)$ association between the other GIPs and sampling season (Table-4). The prevalence of strongyle eggs was the highest (62.9 and 56.3\% for winter and summer seasons, respectively) among the GIP infections in different seasons.

\section{Discussion}

Gastrointestinal parasitism is a major health problem affecting the productivity of goat farming worldwide $[6,10,11]$. The overall GIP prevalence of $37.08 \%$ observed in the present study is, however, lower than the prevalence of GIPs in goats in Cameroon (90.04\%) [40], Bangladesh (77.0\%) [41],

Table-1: Prevalence (\%) of gastrointestinal parasitic infections in South African goat communities in different AEZs.

\begin{tabular}{|c|c|c|c|c|c|c|c|}
\hline \multirow{2}{*}{$\begin{array}{l}\text { Gastrointestinal } \\
\text { parasite }\end{array}$} & \multicolumn{4}{|c|}{ AEZ } & \multirow[t]{2}{*}{ Overall } & \multicolumn{2}{|c|}{ Chi-square test } \\
\hline & Arid $(n=80)$ & Semi-arid $(n=76)$ & $\begin{array}{c}\text { Dry sub-humid } \\
(n=70)\end{array}$ & $\begin{array}{l}\text { Humid } \\
(n=62)\end{array}$ & & $\chi^{2}$-value & p-value \\
\hline Eimeria spp. & 27.5 & 26.3 & 33.6 & 33.9 & 30.0 & 3.19 & 0.36 \\
\hline Trichuris & 22.5 & 21.1 & 28.6 & 35.5 & 26.4 & 8.96 & 0.03 \\
\hline $\begin{array}{l}\text { Strongyloides } \\
\text { papillosus }\end{array}$ & 28.8 & 32.2 & 32.9 & 30.7 & 31.1 & 0.72 & 0.87 \\
\hline Moniezia spp. & 27.5 & 42.8 & 40.0 & 37.1 & 36.6 & 8.91 & 0.03 \\
\hline Strongyles & 46.9 & 57.2 & 72.1 & 64.5 & 59.6 & 21.5 & 0.00 \\
\hline Overall & 30.6 & 35.9 & 41.4 & 40.3 & 37.1 & & \\
\hline
\end{tabular}

$\chi^{2}=$ Chi-square, $\mathrm{AEZ}=$ Agro-ecological zones

Table-2: Prevalence (\%) of gastrointestinal parasites in goats of different ages.

\begin{tabular}{|c|c|c|c|c|c|}
\hline \multirow[t]{2}{*}{ Gastrointestinal parasite } & \multicolumn{3}{|c|}{ Goat age } & \multicolumn{2}{|c|}{ Chi-square test } \\
\hline & Suckling $(n=88)$ & Young $(n=110)$ & Adult $(n=378)$ & $\chi^{2}$-value & p-value \\
\hline Eimeria spp. & 23.9 & 48.2 & 26.2 & 21.5 & 0.001 \\
\hline Trichuris & 20.5 & 37.3 & 24.6 & 8.87 & 0.01 \\
\hline Strongyloides papillosus & 12.5 & 50.0 & 29.9 & 32.8 & 0.001 \\
\hline Moniezia spp. & 11.4 & 57.3 & 36.5 & 44.4 & 0.001 \\
\hline Strongyles & 31.8 & 76.4 & 61.1 & 41.4 & 0.001 \\
\hline Overall & 20.0 & 53.8 & 35.7 & & \\
\hline
\end{tabular}

$\chi^{2}=$ Chi-square

Table-3: Prevalence (\%) of gastrointestinal parasitic infections in goats of different sexes.

\begin{tabular}{|c|c|c|c|c|}
\hline \multirow[t]{2}{*}{ Gastrointestinal parasites } & \multicolumn{2}{|c|}{ Goat sex } & \multicolumn{2}{|c|}{ Chi-square test } \\
\hline & Female $(n=374)$ & Male $(n=202)$ & $\chi^{2}$-value & p-value \\
\hline Eimeria spp. & 29.1 & 31.7 & 0.40 & 0.53 \\
\hline Trichuris & 25.1 & 28.8 & 0.83 & 0.36 \\
\hline Strongyloides papillosus & 29.1 & 34.7 & 1.86 & 0.17 \\
\hline Moniezia spp. & 38.0 & 34.2 & 0.82 & 0.37 \\
\hline Strongyles & 58.0 & 62.4 & 1.03 & 0.31 \\
\hline Means & 35.9 & 38.3 & & \\
\hline
\end{tabular}

$\chi^{2}=$ Chi-square 
Table-4: Prevalence (\%) of gastrointestinal parasitic infections in goats between seasons.

\begin{tabular}{|c|c|c|c|c|}
\hline \multirow[t]{2}{*}{ Gastrointestinal parasite } & \multicolumn{2}{|c|}{ Season } & \multicolumn{2}{|c|}{ Chi-square test } \\
\hline & Winter $(n=288)$ & Summer $(n=288)$ & $\chi^{2}$-value & p-value \\
\hline Eimeria spp. & 34.0 & 26.0 & 4.37 & 0.04 \\
\hline Trichuris & 27.4 & 25.4 & 0.30 & 0.59 \\
\hline Strongyloides papillosus & 32.3 & 29.9 & 0.40 & 0.53 \\
\hline Moniezia spp. & 37.5 & 35.8 & 0.19 & 0.67 \\
\hline Strongyles & 62.9 & 56.3 & 2.60 & 0.11 \\
\hline Means & 38.8 & 34.7 & & \\
\hline
\end{tabular}

$\chi^{2}=$ Chi-square

and India (51.89\%) [42]. Strongyle infection was the most commonly observed (64.5\%) GIP infection among those observed in the present study. Our observations were similar to those of some other studies conducted in Africa and abroad, which described strongyle infection as a major problem in small ruminants [43]. However, several authors have previously reported that Eimeria spp. infection is the most prevalent among GIP in goats [44-46]. The present finding that the overall prevalence of Trichuris and S. papillosus was 26.4 and $31.8 \%$, respectively, differs from the findings of Ntonifor et al. [40] who reported a prevalence of 13.9 and $48.9 \%$, respectively. This difference may be attributed to different sampling sites, size and years, goat breed, and agro-climatic conditions.

The significant association observed between the AEZ and the prevalence of strongyle, Trichuris, and Moniezia spp. might be due to geographical and AEZ climatic variability, the number of animals included in various AEZs, and the management practices adopted locally. The lower prevalence of strongyles, Trichuris, and Moniezia spp. in arid zones may be attributed to the fact that these areas are extremely warm and receive scarce, erratic rainfall $[47,48]$, which is unfavorable for GIP development, survival, and transmission $[34,49]$.

The higher prevalence of strongyles, Trichuris, and Moniezia spp. in dry-humid and humid zones may be attributed to the fact that these areas have higher rainfall and humidity, plus moderate temperatures $[47,48]$, which are therefore suitable for fecundity and epidemiology of the GIP. Another contributing factor may be due to poor farm management techniques and generally unhygienic farming conditions. In the present study, the prevalence of Trichuris, S. papillosus, Moniezia, and strongyle infections in semi-arid regions was higher than the findings in the same AEZ of Udgir, India [42]. The occurrence of Moniezia spp. in the tropics is associated with the ingestion of oribatid mites infected with cysticercoids of Moniezia spp. [40]. However, the prevalence of Eimeria spp. in the semi-arid zone $(26.3 \%)$ was not comparable to the prevalence in semi-arid zones in India (71.45\%) [46] and Ethiopia (15.7\%) [50]. The prevalence of Trichuris spp. (21.0\%) was also not comparable to that reported in the semi-arid zone in Ethiopia (0.3\%) [50]. Agro-ecological factors are very important for the hatching of viable eggs, as well as parasite survival and development [51,52], leading to differences in GIP prevalence. The interactions between host factors and parasite factors determine the potential for disease/infection to occur and the pattern of infection, whereas host-environment and parasite-environment interactions influence disease transmission [53].

Infections with GIPs were more prevalent in young goats than in adult and suckling goats. Young animals are susceptible to infections due to their immunological immaturity and unresponsiveness [54], failure to separate young stock from the adult stock at the pre-weaning age, and overgrazing of infested pasture [55]. Adult animals may acquire immunity to the parasite through frequent challenges and may expel the ingested parasite before an infection is established $[45,56]$. The present findings agree with findings from several other studies $[25,41,55]$, in which young goats showed a higher incidence of parasitic infection than adult goats. However, some researchers have noticed a higher prevalence in adults than in young goats [57-59].

Contrary to the present findings that goat age was significantly associated with the prevalence of GIPs, several authors $[27,32,42]$ observed that the age of the animals was not significantly associated with the prevalence of the GIP. Furthermore, in contrast to the findings of the present study, Verma et al. [46] reported that suckling goats were more heavily infected with Eimeria and Moniezia spp. than young or adult goats. The overall prevalence of GIPs in suckling goats found in this study $(20.0 \%)$ is, however, lower than the prevalence observed by Radfar et al. [60] and Dappawar et al. [42] who reported a prevalence of 91.42 and $45.0 \%$, respectively, in suckling goats. The overall GIP prevalence of GIPs in adult goats in the present study was also lower than the findings of Radfar et al. [60] (86.8\%), but was higher than the findings of Verma et al. [46]. The prevalence of Trichuris spp. in the present study was lower than that observed by Radfar et al. [60].

The sex-wise prevalence analysis revealed that GIP infection occurred with similar frequency in males and females, which can be attributed to the fact that both sexes are kept under similar management systems. On contrary, the significant association between goats' sex and the prevalence of GIP was previously reported to occur more frequently in males than in females [42] or in females more than 
males [27,32,41]. Similar to the findings of Dappawar et al. [42], the percentage of Trichuris and S. papillosus infections between the two sexes was marginally higher in males as compared to females in our study. However, contrary to the findings of Dappawar et al. [42] and Verma et al. [46] who observed higher infection rates in females than in males, we observed that the prevalence of strongyles was marginally higher in males.

There was no significant association between the prevalence of Trichuris, S. papillosus, Moniezia spp., and strongyles during winter and summer seasons, which is noteworthy since one could anticipate that the arthropod intermediate hosts would be favored by a moist microclimate in the pasture. Similar observations were also previously reported [61]. A significant association between season and GIP prevalence was previously reported $[41,42]$. The significantly $(\mathrm{p}<0.05)$ higher prevalence of Eimeria spp. observed in winter could be attributed to the fact that the Eimeria spp. development, survival, and reproduction highly depend on seasonal factors. The nematode infections can be carried over from one favorable season to another within the host animal, which may explain the continued presence of worms in animals even during unfavorable season precluding development and survival of nematodes [62].

\section{Conclusion}

GIPs are of economic importance and pose a great challenge to goat farmers in different AEZs. The GIPs are prevalent and endemic to a considerable extent among the goats in the study area of South Africa. AEZ and goat age were the most important factors influencing the risk of GIP infections in South African goat communities. These risk factors need to be taken into consideration when designing effective parasite control management systems for these animals. The present study validates the need to create awareness to develop the appropriate educational materials for goat farmers and the general public regarding infection potential, the dangers these GIPs pose, and possible ways to combat them. Further detailed investigations into the infestation intensity and patterns, as well as other epidemiological factors, should be carried out to generate a comprehensive parasite profile of South African goat community.

\section{Authors' Contributions}

This study is the component of the work toward the Ph.D. thesis of the first author TJM, under the guidance of KAN and BM. TJM designed the study, collected, and analyzed the data, and wrote the manuscript. KAN and BM designed the study, coordinated the work, and revised the manuscript. All authors read and approved the final manuscript.

\section{Acknowledgments}

The authors are grateful to Goodness Thobela, Phuti Masoga, Phumla Mbeetse, and Ripfumelo
Mabunda, communal goat farmers and Veterinary Officers in Kwa-Zulu Natal, Limpopo, and Mpumalanga provinces, South Africa for their participation in this study. The National Research Foundation (Grant: 112055), South Africa is acknowledged for financial assistance.

\section{Competing Interests}

The authors declare that they have no competing interests.

\section{Publisher's Note}

Veterinary World remains neutral with regard to jurisdictional claims in published institutional affiliation.

\section{References}

1. Homann, S., Van Rooyen, A., Moyo, T. and Nengomasha, Z. (2007) Goat production and marketing: Baseline information for semi-arid Zimbabwe. ICRISAT. Available from: http://www.icrisat.org/Publications-2007. Accessed on 20-04-2014.

2. Ruto, E., Garrod, G. and Scarpa, R. (2008) Valuing animal genetic resources: A choice modeling application to indigenous cattle in Kenya. J. Agric. Econ., 38(1): 89-98.

3. Sweet, R.J. (2008) Managing and developing African Pastoralism: Some practical considerations. Grassroots, 8(2): 2 .

4. Teklye, B. (1991) Epidemiology of endoparasites of small ruminants in Sub-Saharan Africa. In: The Proceedings of Fourth National Livestock Improvement Conference, Addis Ababa, Ethiopia. p7-11.

5. Mandonnet, N., Aumont, G., Fleury, J., Arquet, R., Varo, H., Gruner, L., Bouix, J. and Khang, J.V. (2001) Assessment of genetic variability of resistance to gastrointestinal nematode parasites in Creole goats in the humid tropics. J. Anim. Sci., 79(7): 1706-1712.

6. Sissay, M., Asefa, A., Uggla, A. and Waller, P. (2006) Anthelmintic resistance of nematode parasites of small ruminants in eastern Ethiopia: Exploitation of refugia to restore anthelmintic efficacy. Vet. Parasitol., 135(3-4): 337-346.

7. Pomroy, W.E., Lambert, M.G. and Betteridge, K. (1986) Comparison of fecal strongylate egg counts of goats and sheep on the same pasture. N. Z. Vet. J., 34(3): 36-37.

8. Mckenna, P.B. and Watson, T.G. (1987) The comparative efficacy of four broad-spectrum anthelmintics against some experimentally induced trichostrongylid infections in sheep and goats. N. Z. Vet. J., 35(11): 192-195.

9. Hoste, H., Torres-Acosta, J.F. and Aguilar-Caballero, A.J. (2008) Nutrition parasite interactions in goats: Is immunoregulation involved in the control of gastrointestinal nematodes? Parasite Immunol., 30(2): 79-88.

10. Sutherland, I. and Scott, I. (2010) Gastrointestinal Nematodes of Sheep and Cattle: Biology and Control. Wiley-Blackwell Publishing, Sussex, UK. p242.

11. McRae, K.M., Mcewan, J.C., Dodds, K.G. and Gemmell, N.J. (2014) Signatures of selection in sheep bred for resistance or susceptibility to gastrointestinal nematodes. BMC. Med. Genomics, 15(1): 637.

12. Mohanta, U.K., Anisuzzaman, T., Das, P.M., Majumder, S. and Mondal, M.M.H. (2007) Prevalence, population dynamics and pathological effects of intestinal helminths in black Bengal goats. Bangladesh J. Vet. Med., 5(1-2): 63-69.

13. Zeryehun, T. (2012) Helminthosis of sheep and goats in and around Haramaya, southeastern Ethiopia. J. Vet. Med. Anim. Health, 4(3): 48-55

14. Mbuh, J.V., Ndamukong, K.J.N., Ntonofor, N. and 
Hforlem, G.F. (2008) Parasites of sheep and goat and their prevalence in Bokova, a rural area of Buea subdivision, Cameroon. Vet. Parasitol., 156(3-4): 350-352.

15. Badran, I., Abuamsha, R., Aref, R., Alqisi, W. and Alumor, J. (2012) Prevalence and diversity of gastrointestinal parasites in small ruminants under two different rearing systems in Jenin district of Palestine. An. Najah Uni. J. Res., 26: 1-18.

16. Nye, T.L. and Moore, R. (2004) Meat Goat Production and Budgeting Ohio line. Ohio State University, Ohio.

17. Hoste, H., Jackson, F., Athanasiadou, S., Thamsborg, S.M. and Hoskin, S.O. (2006) The effects of tannin-rich plants on parasitic nematodes in ruminants. Trends Parasitol., 22(6): 253-261.

18. Waller, P.J. (2006) Sustainable nematode parasite control strategies for ruminant livestock by grazing management and biological control. Anim. Feed Sci. Tech., 126(3-4): 277-289.

19. Pal, R.A. and Qayyum, M. (1992) Breed, age and sex-wise distribution of gastro-intestinal helminths of sheep and goats in and around Rawalpindi region. Pak. Vet. J., 12(2): 60-63.

20. Kumar, B., Maharana, B.R., Prasad, A., Joseph, P.J., Patel, B. and Patel, J.S. (2016) Seasonal incidence of parasitic diseases in bovines of South Western Gujarat, India. $J$. Parasit. Dis., 40(4): 1342-1346.

21. Godara, R., Katoch, R., Yadav, A. and Rastogi, A. (2014) Epidemiology of paramphistomosis in sheep and goats in Jammu, India. J. Parasit. Dis., 38(4): 423-428.

22. Khajuria, J.K., Katoch, R., Yadav, A., Godara, R., Gupta, S.K. and Singh, A. (2012) Seasonal prevalence of gastrointestinal helminths in sheep and goats of middle agro-climatic zone of Jammu province. J. Parasit. Dis., 37(1): 21-25.

23. Lone, B.A., Chishti, M., Ahmad, F. and Tak, H. (2012) A survey of gastrointestinal helminth parasites of slaughtered sheep and goats in Ganderbal, Kashmir. Glob. Vet., 8(4): 338-341.

24. Ayaz, M.M., Raza, M.A., Murtaza, S. and Akhtar, S. (2013) Epidemiological survey of helminths of goats in Southern Punjab, Pakistan. Trop. Biomed., 30(1): 62-71.

25. Zvinorova, P.I., Halimani, T.E., Muchadeyi, F.C., Matika, O., Riggio, V. and Dzama, K. (2016) Prevalence and risk factors of gastrointestinal parasitic infections in goats in low-input low-output farming systems in Zimbabwe. Small Rumin. Res., 143: 75-83.

26. Raza, M.A., Iqbal, Z., Jabbar, A. and Yaseen, M. (2007) Point prevalence of gastrointestinal helminthiasis in ruminants in southern Punjab, Pakistan. J. Helminthol., 81(3): 323-328.

27. Emiru, B., Ahmed, Y., Tigre, W., Feyera, T. and Deressa, B. (2013) Epidemiology of gastrointestinal parasites of small ruminants in Gechi district, Southwest Ethiopia. Adv. Biomed. Res., 7(5): 169-174.

28. Vieira, V.D., Feitosa, T.F., Vilela, V.L.R., Azevedo, S.S., de Almeida Neto João Leite de Morais, D.F., Ribeiro, A.R.C. and Athayde, A.C.R. (2014) Prevalence and risk factors associated with goat gastrointestinal helminthiasis in the Sertão region of Paraíba state, Brazil. Trop. Anim. Health Prod., 46(2): 355-361.

29. Boomker, J., Horak, I.G. and Ramsay, K.A. (1994) Helminth and arthropod parasite of indigenous goats in the Northern Transvaal. Onderstepoort J. Vet. Res., 61(1): 13-20.

30. Tsotetsi, A.M. and Mbati, P.A. (2003) Parasitic helminths of veterinary importance in cattle, sheep and goats on communal farms in the northeastern free state, South Africa. $J$. $S$. Afri. Vet. Assoc., 74(2): 45-48.

31. Gwaze, F.R., Chimonyo, M. and Dzama, K. (2009) Communal goat production in Southern Africa: Review. Trop. Anim. Health Prod., 41(7): 1157-1168.

32. Kheirandish, R., Nourollahi-Fard, S.R. and Yadegari, Z. (2014) Prevalence and pathology of coccidiosis in goats in Southeastern Iran. J Parasit. Dis., 38(1): 27-31.
33. Thrusfield, M. (1997) Veterinary Epidemiology. $2^{\text {nd }}$ ed. Blackwell Sciences, Oxford. p182.

34. Hansen, J. and Perry, B. (1994) Epidemiology, Diagnosis and Control of Helminth Parasites of Ruminants. $2^{\text {nd }}$ ed. ILRAD, Nairobi, Kenya. p158-168.

35. Foriet, W. (1999) In: Reference Manual of Veterinary Parasitology. $5^{\text {th }}$ ed. Wiley Blackwell, New York, USA. p22-26.

36. Zajac, M. and Conboy, G. (2006) Veterinary Clinical Parasitology. $7^{\text {th }}$ ed. Black-Well Publishing, Sussex, UK.

37. Van Wyk, J.A., Cabaret, J. and Michael, L.M. (2004) Morphological identification of nematodes of small ruminants and cattle simplified. Vet. Parasitol., 119(4): 277-306.

38. Thrusfield, M. (2005) Veterinary Epidemiology. $3^{\text {rd }}$ ed. Black-Well Publishing, Sussex, UK. p183.

39. MiniTab 17 Statistical Software. (2017) Computer Software. Minitab, Inc., State College, PA. Available from: http://www.minitab.com. Last accessed on 18-07-2019.

40. Ntonifor, H., Shei, S., Ndaleh, N. and Mbunkur, G. (2013) Epidemiological studies of gastrointestinal parasitic infections in ruminants in Jakiri, Bui division, North West region of Cameroon. J. Vet. Med. Anim. Health, 5(12): 344-352.

41. Islam, M.S., Hossain, M.S., Dey, A.R., Alim, M.A., Akter, S. and Alam, M.Z. (2017) Epidemiology of gastrointestinal parasites of small ruminants in Mymensingh, Bangladesh. J. Adv. Vet. Anim. Res., 4(4): 356-362.

42. Dappawar, M.K., Khillare, B.S., Narladkar, B.W. and Bhangal, G.N. (2018) Prevalence of gastrointestinal parasites in small ruminants in Udgir area of Marathwada. J. Entomol. Zool. Stud., 6(4): 672-676.

43. Fikru, R., Teshale, S., Reta, D. and Yosef, K. (2006) Epidemiology of gastrointestinal parasites of ruminant in Western Oromia, Ethiopia. Inter. J. Appl. Res. Vet. Med., 4(1): 51-57.

44. Jatau, I.D., Abdulganiyu, A., Lawal, A.I., Okubanjo, O.O. and Yusuf, K.H. (2011) Gastrointestinal and hemoparasitism of sheep and goats at slaughter in Kano, NorthernNigeria, Sokoto. J. Vet. Sci., 9(1): 7-11.

45. Singh, A.K., Das, G., Roy, B., Nath, S., Naresh, R. and Kumar, S. (2015) Prevalence of gastrointestinal parasitic infections in goat of Madhya Pradesh, India. J. Parasit. Dis., 39(4): 716-719.

46. Verma, R., Sharma, D., Paul, S., Kumaresan, G., Dige, M., Kumar, S.V., Kumar, R.P., Bhusan, S. and Banerjee, S.P. (2018) Epidemiology of common gastrointestinal parasitic infections in goats reared in semi-arid region of India. J. Anim. Res., 8(1): 39-45.

47. Schulze, R.E. (1997) South African Atlas of Agrohydrology and Climatology. Water Research Commission, Pretoria Report TT82/96.

48. Hunters, R.A. and Buck, N. (1992) Nutrition and climatic limits of beef production in the tropics. In: Jarrige, R. and Beranger, C., editors. World Animal Science. C5. Beef Cattle Production. Elsevier Science Publisher, The Netherlands. p379-387.

49. Kumsa, B. and Abebe, G. (2009) Multiple anthelmintic resistance on a goat farm in Hawassa (Southern Ethiopia). Trop. Anim. Health Prod., 41(4): 655-662.

50. Dabasa, G., Shanko, T., Zewdei, W., Jilo, K., Gurmesa, G. and Abdela, N. (2017) Prevalence of small ruminant gastrointestinal parasites infections and associated risk factors in selected districts of Bale zone, southeastern Ethiopia. J. Parasitol. Vector Biol., 9(6): 81-88.

51. Odoi, A., Gathuma, J.M., Gachuiri, C.K. and Omore, A. (2007) Risk factors of gastrointestinal nematode parasite infections in small ruminants kept in smallholder mixed farms in Kenya. BMC Vet. Res., 3(6): 6. Available from: http://www.biomedcentral.com/1746-6148/3/6. Last accessed on 12-07-2019.

52. Ratanapob, N., Arunvipas, P., Kasemsuwan, S., Phimpraphai, W. and Panneum, S. (2012) Prevalence and risk factors for intestinal parasite infection in goats raised in Nakhon Pathom 
province, Thailand. Trop. Anim. Health Prod., 44(4): 741-745.

53. Roeber, F., Jex, A.R. and Gasser, R.B. (2013) Impact of gastrointestinal parasitic nematodes of sheep, and the role of advanced molecular tools for exploring epidemiology and drug resistance-an Australian perspective. Parasit. Vectors, 6(1): 1-13.

54. Asanji, M.F. and Williams, M. (1987) Variables affecting the population dynamics of gastrointestinal helminth parasites of small ruminants in Sierra leone. Bull. Anim. Health Prod., 35(40): 387-313.

55. Ndamukong, K.N.J. (1985) Strongyle infestations of sheep and goats at Mankon station, Mankon station, Bamenda, Cameroon. Vet. Parasitol., 1(4): 95-101.

56. Shah-Fischer, M. and Say, R. (1989) Manual of Tropical Veterinary Parasitology. CAB International; the Technical Center for Agricultural and Rural Cooperation (CTA). CAB International, Wallingford, UK.

57. Uddin, M.Z., Farjana, T., Begum, N. and Mondal, M.M.H. (2006) Prevalence of amphistomes in Black Bengal goats in Mymensingh district. Bangladesh J. Vet. Med., 4(2): 103-106.
58. Hassan, M.M., Hoque, M.A., Islam, S.K.M., Khan, S.A., Roy, K. and Banu, Q. (2011) A prevalence of parasites in black Bengal goats in Chittagong, Bangladesh. Int. J. Livest. Prod., 2(4): 40-44.

59. Admasu, P. and Nurlign, L. (2014) Prevalence of gastrointestinal parasites of small ruminants in Kuarit district, North West Ethiopia. Afr. J. Bas. Appl. Sci., 6(5): 125-130.

60. Radfar, M.H., Sakhaee, E., Bafti, M.S. and Mohammadi, H.H. (2011) Study on gastrointestinal parasitic infections of Raeini goats. Iran. J. Vet. Res., 12(1): 76-80.

61. Sissay, M.M., Uggla, A. and Waller, P.J. (2007) Prevalence and seasonal incidence of nematode parasites and fluke infections of sheep and goats in Eastern Ethiopia. Trop. Anim. Health Prod., 39(7): 521-531.

62. Nwosu, C.O., Madu, P.P. and Richards, W.S. (2007) Prevalence and seasonal changes in the population of gastrointestinal nematodes of small ruminants in the semi-arid zone of North-Eastern Nigeria. Vet. Parasitol., 114(1-2): 118-124.

\section{$* * * * * * * *$}

